\title{
Landscape Studying of Traditional Settlement Based on local Culture
}

\author{
Nan Hong ${ }^{1, a}$, Han Xiuru ${ }^{2, b}$ \\ ${ }^{1,2}$ Qinghai University, Xining, China \\ A,bqddqp@163.com
}

Keywords: Traditional settlement, landscape, culture, preservation, reconstruction.

\begin{abstract}
With the development of the major on modern landscape design, the contents of it have been changed from beautifying the environment or land arrangements into the way of spatial analysis, planning, design, management, recovery and comprehensive, and with the major of architecture and city planning, landscape has become one of the three majors which based on human settlement environment construction. My current research in this article contains three kinds of culture. They are Chinese minority culture, the rural local culture and the historical culture. The three points are the impact of landscape pattern by culture, the preservation on traditional settlement based on culture and the reconstruction on rural settlements with protection on culture. Impact factor, the preservation and reconstruction constitute three steps of the process on landscape planning of traditional settlement. At the same time, the culture and human settlements are destroying with this process in China while emerging more and more problems during construction of Chinese new rural. This article considers ways of field investigation and case study to compare the situation between China and Japan then sum up planning experience of traditional settlement in Japan based on culture, so that we can balance and correct the developing ways of settlement reconstruction and the relevant culture in China.
\end{abstract}

\section{Research Review}

Research significance and background. Following intermingle with the concept of ecology design into the landscape discipline, the position of cultural factors in landscape design has become increasingly prominent. A series of cultural landscape concepts like the vernacular landscape or genius loci have become the important elements when people are trying to plan a characteristic local landscape. Exploring regional culture based on the development of landscape space has become the supporting elements and the design basis, and at the same time, it's the important reason for the identifiable on landscape design.

The forum of global human settlements environment continuously put forward the themes about constructing sustainable human settlements development and characteristic livable city, we're far away from these aims, although we have made great achievements in economic development after the past 30 years in China with fast urbanized development. The sites of ancient villages were destroyed and the historical settlements were removed. It not only made us lose a large number of material cultural heritage while the replacement by many-storied buildings lead to each city may lost its symbols and characteristics, but also had emerged the undesirable phenomenon of "village of a thousand' and deterioration of the living environment in the background of new rural construction. A vicious spiral is circulating together with the loss of logical culture.

The formation and development of settlements have become hot theme of current research, whether city or country both can be regarded as the human settlement and their scale formation and development history are traceable. People are trying to achieve to develop livable and sustainable human settlements through the study of the settlement space research. Actually local culture is an important factor to affect the settlement pattern. Studying on the effect of different areas by native culture in China on the settlement landscape pattern can provide a healthier and more sustainable development orientation for the future to the new rural planning and construction or for the urban plan while easing the problem of losing native architecture and landscape characteristics, also including the deterioration of the environment and loss of cultural heritage nowadays.

The main content of this paper is the impact of landscape pattern on the folk houses and 
settlement based on the local culture. Aim to explore the interactive relationship and impaction between the local culture and the human settlement spatial pattern. Especially in some Chinese ethnic settlements, we need to strive to protect of the original ecology of the natural environment and cultural landscape in the minority area while reducing the loss of characteristics on cultural elements to create a green and sustainable development ecological residence the on the Tibetan Plateau.

The purpose for choosing traditional settlement as my research target is that our inhabited environment is the evolution from settlement actually. In a state of nature, from a village to a town until became a city, they all originated from basic settlement so we may use it as reference to the bigger scale. And the second reason for that is traditional settlements have distinctive cultural characters from different regions which can show the diversity of landscape architecture and local culture in the word. No matter what kind of culture or region the traditional settlements belong to, they all have their own characters and functions to adopt the local natural conditions better and can show the human wisdom of technologies and development on landscape and architecture. This is valuable for us to study the suitability and functionality of human settlement.

Now there are more than 5000 ancient traditional settlements in China but we have lost 900,000 ancient towns during the past 20 years. About 200 traditional settlements have been preserved and exploited so far and the wave of new rural construction is also sweeping across China. We not only have no time to introspect the destruction of landscape and culture but also have to face new problems during preservation and reconstruction.

Table 1.the present situation with the problems and influence on traditional settlement construction in China

Present Situation

Without analyzing the impact factors of landscape formation based on culture

No protection on the culture during preservation

No respect and inheritance for the culture during reconstruction or relocation
Resulting Problems

Just focus on the economic interest and political benefits

Original site and pattern was demolished and new constructions for commercial and tourism use

All the new rural settlements have same features; the culture and landscape or architecture heritage disappeared
Influence

(1)The transform of
custom, suitability and
unctionality for dwellers;
(2) Waste the finance and
and resources and expel
the dwellers;
Distinctive culture and
landscape architecture
disappear then lost
direction on their
elopment and planning.

Chinese modern landscape follows western modern landscape and loses its own tradition which is becoming more uniformity and lacking human concern. The history of Japanese garden resembles Chinese ancient garden but they have found an appropriate way of inheriting and developing traditional culture to become famous and successful in the world finally. This experience should be referenced by Chinese landscape architecture. So studying on the landscape of traditional settlements based on culture in Japan and the design methods for focusing on the details and human concern and compare with Chinese and to improve its shortages is my purpose.

Research ways and objectives

This paper mainly has two research ways to study the landscape pattern based on the local culture. They are the method of comparison and the method of literature review. Comparing the situation between China and Japan to analysis the development and differences during the construction and protection. Firstly to study what kind of cultural factors would impact the landscape pattern more in Japanese and Chinese traditional settlements from the three points of religion culture, ethnic culture, local custom. Secondly to study how to balance the commercial exploitation and tourism during 
preserve the traditional settlements and thirdly to discuss whether need to create an ideal model before reconstruct the new rural settlements and order dwellers to copy it. Compare the situation of constructing same structures and painting the whole village in a same color between China and Japan. At last study the situation that the studying of landscape on traditional settlement can be used for landscape architecture in other places and situations.

Study on traditional settlements need to take methods of field investigation and case study mainly to study. Field investigation need two points: (1) Go to the field to record situation by myself as possible as I can; (2) Choose the traditional settlement which with a relatively wide range as my research objectives to summarize the characters more comprehensive. Case study is a summary of preservation and conservation on landscape architecture which comes from finished traditional settlements. Using this method could perfect the information and understanding from field investigation. At last, I have a questionnaire to investigate the cognition of local culture for original dwellers after their settlement has been preserved or reconstructed. To compare with the situations in China and study whether inheriting of local culture would be impacted by cultural landscape.

To study and analysis the garden and the space of the settlement streets, the courtyard and architecture of traditional settlements in Japan.

To study how to combine the comfort in life and the aesthetic on landscape through the examples of traditional settlements and the situation of commercial or tourism exploitation and culture protection in traditional settlements in Japan.

To study the methods of reconstruct or remove on traditional settlements in Japan.

To solve my problems put forward above and compare those situations between China and Japan which can be useful to sum up some experience to be applied in China.

To study how to deal with the details and human concern in Japanese landscape works.

\section{Preliminary literature review}

The landscape evolution of Chinese traditional settlement. The evolution of landscape pattern based on Chinese traditional settlement has two situations until now: natural organic evolution and rational human planning. Both of them have recorded the culture's transition and the culture also has impacted the pattern of the settlements. With these characters on coordinating with nature organically, revealing local life and culture, the natural evolution has more advantage than rational human planning. It is because of adopting overmuch human planning in settlement's construction which focuses on abstract and orderly pattern or aesthetic and makes the settlements lack vitality and livability, furthermore cut off the inheritance on culture. It is thus clear that traditional settlement can provide a developing environment to preserve the intangible cultural heritage. The new rural settlements in China are usually orderly, featureless and the functions among them have no organic connection, especially lack of the humanistic concern.

The forum of global human settlements environment continuously put forward the themes about constructing sustainable human settlements development and characteristic livable city, we're far away from these aims, although we have made great achievements in economic development after the past 30 years in China with fast urbanized development. The sites of ancient villages were destroyed and the historical settlements were removed. It not only made us lose a large number of material cultural heritage while the replacement by many-storied buildings lead to each city may lost its symbols and characteristics, but also had emerged the undesirable phenomenon of 'village of a thousand' and deterioration of the living environment in the background of new rural construction. A vicious spiral is circulating together with the loss of logical culture.

The formation and development of settlements have become hot theme of current research, whether city or country both can be regarded as the human settlement and their scale formation and development history are traceable. People are trying to achieve to develop livable and sustainable human settlements through the study of the settlement space research. Actually local culture is an important factor to affect the settlement pattern. Studying on the effect of different areas by native culture in China on the settlement landscape pattern can provide a healthier and more sustainable development orientation for the future to the new rural planning and construction or for the urban plan 
while easing the problem of losing native architecture and landscape characteristics, also including the deterioration of the environment and loss of cultural heritage nowadays.

\section{The impact of landscape pattern of traditional settlement based on culture}

Traditional settlement may be classified as three scales like table 2.

Table 2.Three scales of traditional settlement in China

\begin{tabular}{|c|c|}
\hline scale & Function \\
\hline Ancient village & The functions for living and production \\
\hline Ancient town & Main function is Living area but with the functions of commerce and trade \\
\hline Ancient city & Functions of residence, commerce, military defense and political \\
domination
\end{tabular}

From ancient village to ancient city, with the development of their scales there will be more and more culture factors which come from commercial trade and minority communication impact the landscape pattern on traditional settlements. At the same time, the settlements can show diversity of landscape architecture and culture.

Table 3.Impaction on traditional settlements by different types of culture

\begin{tabular}{|c|c|c|c|}
\hline Culture types & Contain & Influence & Example settlement \\
\hline $\begin{array}{c}\text { Minority } \\
\text { culture }\end{array}$ & $\begin{array}{c}\text { Religion faith, ethnic } \\
\text { custom }\end{array}$ & $\begin{array}{c}\text { architectural appearance, } \\
\text { decoration, architectural } \\
\text { space, landscape garden }\end{array}$ & $\begin{array}{c}\text { Hani minority traditional } \\
\text { settlement in Yunnan } \\
\text { Province }\end{array}$ \\
\hline Local culture & $\begin{array}{c}\text { clan relatives, local } \\
\text { custom and Feng } \\
\text { skill for keeping a } \\
\text { balance of forces on } \\
\text { living area with } \\
\text { surroundings) }\end{array}$ & $\begin{array}{c}\text { Site Selection, courtyard } \\
\text { appearance and space, } \\
\text { landscape garden }\end{array}$ & Wu Zhen ancient town in \\
Zhejiang Province
\end{tabular}

In fact, the three types of culture usually have a comprehensive effect on traditional settlement but if one type among them starts to change, there will be a completely different result. For example, Zang and Tu minority in China all believe in Tibetan Buddhism but because of different local culture, their temples and pagodas are located in different areas in their own traditional settlements. It makes the landscape pattern start to change.

The study on landscape of traditional settlement in Japan. The study on traditional settlement in Japan is more mature than China. They are not only be preserved completely, but also be exploited moderately. Japanese rural landscape management and social management system are complete. These are very important protecting factors for traditional settlements. The Gassho Village in Shirakawa Japan is a worth example to learn which focuses on protecting local culture and original rural landscape pattern. Meanwhile, it has well fire protection to make the settlement avoid destruction by fire. In addition, the most popular theory in the industry of Landscape Architecture in Japan--'Satoyama' can give us lessons for the development of Chinese new rural construction and landscape. To analyze the combination of the theory and practice of rural landscape planning based on 'Satoyama', two cases of rural landscape, 'Okutama forestry therapy road' and the 'Echigo 
tsumari art field' show me some advanced means of Japanese rural landscape planning and design field in today, like transform the space of forest from walking to stay for using this site more suitably and use the farmland and deserted school for alteration to preserve local culture. And with the case study of Public Space Design of Kyoto Station, I find that the settlement research has been used in the other situation of landscape architecture - public activity space. It reflects and uses the settlement characters of field, topography and order in the chaos to make people feel friendly to the space and communicate easily in the space.

\section{Discussion}

The main content of this paper is the impact of landscape pattern on the folk houses and settlement based on the ethnic culture. Aim to explore the interactive relationship and impaction between the national culture and the ethnic settlement spatial pattern. We need to strive to protect of the original ecology of the natural environment and cultural landscape in the minority area while reducing the loss of characteristics on cultural elements to create a green and sustainable development ecological residence in China.

\section{Acknowledgements}

2013Enhance the Comprehensive Strength and the Special-High-Level Talent introduction construction project in the Midwest of China.

\section{References}

[1] Liu Xiaoxing. Study on Organic Evolution of Chinese Traditional Settlement and Some Revelations [J]. Urban Planning Forum, 2007(9):55-60

[2] Liu Peilin. Landscape Division of Traditional Settlement and Effect Elements of Landscape Gene in China [J]. ACTA GEOGRAPHICA SINICA, 2010(12):1496-1506

[3] Li Dafang. Space Composition of Traditional Tibetan Settlements Space in Danba [J]. Landscape Architecture, 2013(10):110-117

[4] Liu Peilin. Characteristic and Genes--Analysis of Traditional Settlements' Landscapes in Chinese Minority Areas [J]. ACTA GEOGRAPHICA SINICA, 2010(12):810-816

[5] Gu Xiaoling. On the Essence and Enlightenment of the Architecture - thinking from 'What is the Architecture' to 'How to Build the Architecture' [J]. Architecture \& Culture, 2013(03):91-92

[6] Bu Jinghua. Village Construction-Public Space Design of Kyoto Station and Village Research by Hara Hiroshi [J]. ARCHITEAURAL FORUM, 2005(06):29-31

[7] Liu Peilin. Study of landscape-image of Chinese ancient village [J]. ACTA GEOGRAPHICA SINICA, 1988(3):31-38

[8] Xin Boyu. Study on Rural Landscape in Japan [D]. Beijing: Beijing Forestry University, 2013

[8] Zhang Junhua. Landscape Thoughts [M]. China Architecture \& Building Publishing, Beijing. 2010

[9] Zhang Junhua. Landscape Heritage [M]. China Architecture \& Building Publishing, Beijing. 2011

[10] Fujii Akira. Settlement Research [M]. China Architecture \& Building Publishing, Beijing. 2003 